\title{
CONSTRUINDO COM A EQUIPE DE ENFERMAGEM \\ O COMPROMISSO SOCIAL DE AJ UDAR A FAMÍLIA DO CLIENTE DE UMA UNIDADE CIRÚRGICA COM BASE NO REFERENCIAL DE TRAVELBEE
}

\author{
THE PROCESS OF BUILDING THE SOCIAL COMMITMENT OF HELPING \\ THE FAMILY OF THE CUSTOMER OF A SURGICAL UNIT BASED \\ IN TRAVELBEE ALONG WITH THE NURSING TEAM \\ CONSTRUYENDO CON ELEQUIPO DE ENFERMERÍA \\ EL COMPROMISO SOCIAL DE AYUDAR A LA FAMILIA DEL CLIENTE DE \\ UNA UNIDAD DE CIRUGÍA CON BASE AL REFENCIAL DE TRAVELBEE
}

Dalva Irany Grüdtner*

A família é considerada a base da civilização e dos relacionamentos humanos.

SCHELESSINGER

\begin{abstract}
RESUMO: Trata-se do relato de um programa desenvolvido em conjunto com a equipe de Enfermagem de um hospital escola, que objetivava suscitar compromisso social desta para com a família do cliente hospitalizado, crescimento e desenvolvimento das potencialidades dos atores. Teve como referencial teórico conceitos da teoria das Relações Interpessoais e da Pedagogia Problematizadora. Metodologicamente utilizou estratégias de oficinas, entrevistas e troca informal. Foi observado o rigor ético no conta to com os sujeitos e tratamento dos dados. A análise foi iluminada pelo referencial teórico e experiência profissional da autora. Os resultados mostram que a equipe vê como vantagem ter a família como parceira; trabalhar o tema morte levou-os a reconhecerem sua finitude; admitem que há barreiras institucionais para o contato entre a família e o cliente. Avaliam a proposta como oportunidade de conscientização do papel da Enfermagem à família que deve ter continuidade e ser expandida a todos setores do hospital.
\end{abstract}

DESCRITORES: Equipe de enfermagem; Saúde da família.

\section{INTRODUÇÃO}

Atuando como docente há quase uma década, em unidade de internação cirúrgica de um hospital escola, percebi uma interface que a Enfermagem ainda precisava explorar, a das necessidades dos familiares de clientes submetidos à cirurgia.

A parte prática da disciplina na área da Enfermagem Cirúrgica é planejada para o turno matutino, enquanto que o horário permitido à entrada de visitas, é no vespertino, de maneira que os acadêmicos não têm quase contato com a família antes do dia da cirurgia. E quando finalmente chega este dia, os parentes conseguem ter um encontro rápido com o familiar - antes deste ir para o Centro Cirúrgico. Caso contrário, ele vai solitário, sem fazer as últimas recomendações ou sentir um afago "familiar" (Grüdtner, 1997).

No projeto da Prática Assistencial, como atividade do curso de mestrado, planejei um programa de aprender-ensinar a ajudar a família do indivíduo operado, envolvendo os docentes da disciplina em que atuo, discentes, clientes e seus familiares. Embora, inicialmente tivesse previsto incluir nesse processo a equipe de

* Enfermeira Professora Adjunta do Departamento de Enfermagem da UFSC; Mestre em Assistência de Enfermagem; Aluna do Telecurso de Especialização em Violência Doméstica Contra Criança e Adolescente - USP; Doutoranda em Enfermagem e membro do GAPEFAM. E-mail: dig@ icablenet.com.br 
Enfermagem da CCR I, na prática não foi possível. Pois ao desenvolver a atividade de docente e de pesquisadora, era quase que totalmente absorvida por esses dois papéis, não dispondo de tempo suficiente para realizar reflexões com aquela categoria, deixando exposta a necessidade de aprofundamento.

A impossibilidade de refletir também as questões com a equipe de Enfermagem durante o trabalho acadêmico, manteve-me alerta para retornar e empreender um programa que comportasse a dimensão do desenvolvimento de todos os seres humanos envolvidos no processo de ajudar a família do cliente operado.

Além disso eles teriam a oportunidade de ver que o que sabem, sentem e fazem, influi no comportamento das pessoas que os cercam. Contemplando então meu anseio de oportunizar aos componentes da equipe assistencial desenvolverem-se como seres humanos, enquanto é compartilhado o saber relativo a ajuda à família do cliente operado. Pois, atuando junto a essa família, é possível levá-la a lograr um nível melhor de qualidade de vida, ao refletir junto e incentivando a buscar auxílio dentro da sua própria comunidade, quando necessário.

\section{FUNDAMENTAÇÃO TEÓRICA}

\section{ESTADO DE ARTE DO AJUDAR A FAMÍLIA NOS SERVIÇOS DE SAÚDE}

Santos (1996) declara que a educação de Enfermagem na área da prática profissional com famílias, está ainda em estado de arte. Há uma desvinculação entre o ensino e a prática, embora seja filosofia dos serviços de saúde ajudar as famílias, isto não é desenvolvido de forma efetiva, ao não ser socializado este saber à equipe de Enfermagem. Há, portanto, de suscitar o compromisso desta, para com a família, utilizando estratégias de compartilhar o conhecimento sobre o ajudar a família no hospital.

Elsen (1994) afirma que a Enfermagem, na busca de cuidar da unidade familiar, tem desenvolvido marcos teóricos e conceituais, com o auxílio de conhecimentos de outras áreas, os quais possibilitam compreender seu mundo interior, suas relações com as demais instituições sociais e visualizar possibilidades para a atuação do enfermeiro.

Dessa forma, o trabalho constituiu-se em desenvolver e analisar um programa junto à equipe de Enfermagem de ajuda à família do cliente internado na Clínica Cirúrgica I (CCRI) do Hospital Universitário (HU) da Universidade Federal de Santa Catarina (UFSC). Seus objetivos específicos eram: promover a oportunidade de crescimento e desenvolvimento das potencialidades de todos os seres humanos participantes do programa, oferecer subsídios para ajudar os familiares dos clientes desta clínica e refletir sobre o programa visando seu aprimoramento na continuidade.

Grüdtner (1997) em sua dissertação de mestrado, encontrou que a família de quem passa por uma cirurgia, enfrenta dificuldades, tais como não poder aguardar no quarto do cliente durante o transcurso do ato operatório; não receber informações nesse período, ressaltando a necessidade de ajuda e confirmando que ela é uma unidade da qual a Enfermagem deveria se ocupar.

Por seu termo, Gillis (1989) registra que durante longo tempo, a Enfermagem à família centralizava-se em serviços como a maternidade e pediatria, porque ali havia sempre algum representante da família. Mas, a preocupação com esse familiar era no sentido de instrumentá-lo e torná-lo apto a prestar ajuda/cuidado ao ser doente, mostrando então, que a família é um significativo contexto de ajuda individual. Portanto, continua a referida autora, ver a família como um significativo contexto de ajuda/cuidados para a saúde de seus membros requer reconhecer também que existe uma complexa relação de múltiplos fatores, entre a família e seus membros.

A família pode ser vista como um fator contribuinte que influencia, sob um contexto mais amplo, composto pela comunidade, cultura, política e social, porque ela transita regularmente nesse ambiente. Achados de pesquisas mostram que as interações entre seus membros, concorrem para a saúde da família. Ela é uma poderosa influência na adesão individual ao tratamento, pois clientes crônicos que mantém seu processo de saúde/doença sob controle, pertencem a famílias que têm um bom nível de funcionamento na dinâmica familiar, ressaltando que o estilo da família afeta tanto para o benefício como para o prejuízo, a saúde individual.

Hoje, com poucas exceções, os hospitais têm normas e rotinas rigorosas, em nome de uma assepsia esterilizante da subjetividade das pessoas, o que mantém a família longe do enfermo, tirando-lhes a oportunidade de manter ou fortalecer os laços afetivos entre seus membros. Todavia, é preciso lembrar que o adulto também 
tem fantasias e medos, levando-o a conduzir-se de forma insegura e dependente. Quando se abriu esse espaço na área do adulto, inicialmente era só para os familiares na hora da visita, na iminência de morte ou por necessidade de auxílio nas ações técnicas. Mas, Franco (1988, p. 143) em seus estudos com acompanhantes de adulto hospitalizado, relata que o familiar desse doente, também deseja estar junto dele; por razões como: a necessidade de suprir afeto, de garantir que alguém estará velando por sua segurança - a fim de evitar acidentes - manter-se informado quanto ao diagnóstico. Essa autora detectou também que, há uma outra face da moeda a mover o familiar a querer acompanhar o doente: a gratificação (explicitada como uma oportunidade de sentir-se útil) e igualmente estar tendo a oportunidade de crescimento.

Alguns autores, já a partir do início dos anos 90 do século passado, começaram a ter a mente despertada para a relevância de se lançar um "olhar" aos familiares dos clientes de UTI. Güdtner (1994), encontrou dados reveladores do desejo que a família tem de receber informações seguras - dadas de preferência pelo médico - por sentirem que perderam o contato com o doente e, por conseguinte o controle do tratamento, como se ele passasse a ser propriedade de um grupo de pessoas com quem não tem vínculos. Rosa et al. (1996), em um estudo, buscando identificar as necessidades da família, durante a internação de um de seus membros na UTI, descobriu que as principais necessidades desses familiares são igualmente de ordem psicossocial como segurança emocional, comunicação, amor e gregária. Esse "olhar" ainda foi lançado por Dal Sasso à família que vive a crise de ter um membro com uma doença súbita. Nesse trabalho, a autora perscruta a oportunidade de crescimento dos familiares ao vivenciá-la, uma vez que gera uma situação de crise não somente para 0 paciente mas para toda a família... Recomenda ela que o enfermeiro ao fazer a família aproximar-se de seus pensamentos, imagens e fantasias do inconsciente (...) estimula estes instrumentos de força de modo a fluírem para dentro de cada membro da família como um elixir que os fará crescer, mesmo numa situação de doença (1994, p. 214). Aquela família que traz um membro seu agudamente doente, ou a que chega a procura de alguém, com pouca ou nenhuma informação no Serviço de Emergência, também foi incluída no rol de espaços "olhados" pela Enfermagem. Baptista (1995) tomou o desafio de mostrar que a família neste setor de serviço de saúde, tem necessidade de ajuda da Enfermagem e que é possível prover essa espécie de ajuda ali.

Diante dessas constatações, uma questão se coloca: Como têm reagido os serviços de saúde, frente ao familiar que deseja estar junto de seu parente operado?

Da parte das instituições, o governo via Ministério da Saúde, pelo Sistema Único de Saúde (SUS), estabeleceu o Programa de Saúde da Família (PSF) que é um desdobramento do SUS, lançado como estratégia de reorientação do modelo assistencial. Todavia, mantém uma visão basicamente biologicista, ao empreender medidas para evitar que o homem sadio adoeça, que a doença seja diagnosticada em tempo hábil de ser controlada e que o doente não se complique, invalide ou morra precocemente (Dominguez, 1998, p. 137). É óbvio que, embora aparente um interesse para com o trabalhador, sua preocupação é focalizada na produção que esse ser humano não está em condição de realizar. E os aspectos psicossociais que envolvem sua existência, não são mencionados nem discretamente.

O PSF atribui a direção do seu processo de atenção à saúde à família, por ser esta a célula da sociedade, é também sua primeira unidade de atenção à saúde. Entende portanto, que o cuidado deve ser dado no contexto social do usuário, mas desconsidera as necessidades e os sentimentos das pessoas que têm um familiar doente. Evidencia-se esse programa uma lacuna que o GAPEFAM está buscando preencher, que é ajudar/cuidar a família, isto é, cuidar de quem cuida (Elsen, 1994). Sua visão quer transpor as fronteiras do físico/biológico tão somente, na vigência de algum desequilíbrio no processo saúde/doença, de um membro que, em geral imobiliza as demais pessoas da família, requerendo portanto, ajuda da Enfermagem. Dessa maneira, a visão desse grupo, é também que a equipe, ao ajudar a família através da mobilização de seus recursos internos, da reflexão sobre a realidade imediata, através de ações educativas, estará contribuindo para a transformação dessa realidade e obtendo conseqüentemente o fortalecimento da família, pois os laços foram mantidos ou estabelecidos, ao propiciar o desenvolvimento das potencialidades das pessoas envolvidas, além de promover seu próprio desenvolvimento.

Ainda que influências de um modelo econômico capitalista tenham ditado a arquitetura das instalações hospitalares, não prevendo área física para o familiar acomodar-se perto de seu ente querido, essa família vem ganhando seu espaço. Vemos também ele se abrindo num amplo leque de possibilidades, dantes inimaginadas. Hoje, a família do cliente adulto já tem autorização para permanecer junto a pessoa recém-operada, a despeito 
da inadequação da estrutura, apenas para dar força e coragem à ela, pois para prestar cuidados nem sempre sente-se capaz. Presenciamos ainda a visita ser permitida em horas de refeição para o membro da família ajudar o doente a tomá-la, bem como a de um filho menor, ou a autorização de trazer algum objeto pessoal do cliente, a fim de imprimir um clima "familiar" ao ambiente hospitalar. Os profissionais mais sensíveis às necessidades "do outro", até "desobedecem" o estabelecido burocraticamente, para permitir a entrada de alguém, na iminência de morte de seu familiar, quando então, muitas vezes é a última oportunidade de se restaurar laços quebrados durante um longo período de suas vidas. Sabemos que a falta de perdão tira a paz, principalmente para morrer. De forma que, perdoar ou receber a liberação por erros cometidos em outras épocas, e que só agora, num leito de enfermidade, vem se avaliar a efemeridade da vida e o valor de laços afetivos duradouros, é uma necessidade que na maioria das vezes só a Enfermagem vivência. Embora tenha esse poder nas mãos, nem ela atende este direito que todos temos, o de amor, perdão e de morrer com dignidade. No estágio atual das mudanças no mundo, nos dias de hoje, não temos mais o direito de subtrair esse direito do cliente/familiar.

\section{A PRÁTICA DA EQUIPE DE ENFERMAGEM}

Os educandos têm identificado nos familiares necessidades de: serem ouvidos, receberem informações seriadas durante $o$ transcurso da cirurgia e de terem um profissional seguro por perto, durante esse período.

É conhecida a relação existente entre a qualidade da assistência e o preparo dos trabalhadores. Embora tenha muito interesse na melhoria da qualidade da assistência, essa proposta não se detém aí, ela tem a intenção de que, enquanto promove a melhoria na assistência, esteja também oportunizando o desenvolvimento humano dos trabalhadores da saúde.

\section{ESTRATÉGIAS METODOLÓGICAS}

\section{MARCO CONCEITUAL}

Para delinear o caminhar do grupo de sujeitos que faria o projeto acontecer, elegi alguns conceitos da teoria da Relação Interpessoal de J oyce Travelbee e outros da Pedagogia Problematizadora.

O marcante compromisso para com o outro, o crer no potencial de cada mulher e homem, de Paulo Freire tem atraído meu interesse em trabalhar com as mulheres e os homens da equipe de Enfermagem da CCR I do HU. Assim, vi a possibilidade de implementar a proposta num ambiente, cujos atores são os trabalhadores de saúde, clientes, familiares desses doentes, dentro de um clima de bem querer. Pois é só através da relação com o outro que se a socialização desse saber, ao se desvelar, trabalhar, partilhar valores, crenças e atitudes de cada um.

\section{CONCEITOS}

Uma declaração fundamental da teoria de Travelbee é a de que o ser humano necessita ter a capacidade para amar e ser amado, para desempenhar seus papéis de maneira saudável.

0 conceito Enfermagem Travelbee também o define como um processo interpessoal, no qual o profissional aplica um enfoque intelectual disciplinado aos problemas, como o pensar, dominar os fatos, princípios e conceitos, combinando com esses, a capacidade de usar sua própria pessoa terapeuticamente, para ajudar outras pessoas, famílias e a comunidade a resolver problemas de saúde. Portanto, a enfermeira é uma "facilitadora" interessada em ajudar outros a ajudar-se a si mesmos - tanto na prevenção da enfermidade, como na promoção da saúde - ajudar aqueles que estão incapazes de se ajudar a si mesmos. Para essa autora a relação interpessoal só acontece quando cada participante se percebe como ser humano único e transcende seus papéis, vendo o outro apenas como diferente de si e não como inferior ou superior.

As ações propostas nesse programa transitam concomitantemente do cliente/família para a equipe e vice-versa. Não se pode tomar como prontos e acabados os conhecimentos que já temos sobre o ajudar a 
família. E semelhantemente, não podemos nos deter intelectualmente, mas sim, buscar desenvolver a atitude de pensar criticamente e combiná-la com a capacidade de adaptar-se ou mudar, à medida que surgem novas necessidades, tanto suas como dos clientes/familiares.

A teoria das R elações Interpessoais menciona que na Enfermagem, ela tem ainda a intenção de ajudar o doente/família a encontrar um sentido para a experiência de sofrimento. Entendendo sentido como o conjunto de valores que capacitam o enfermo, não só aceitar a cirurgia em si, bem como a utilizar esses valores para lhe darem suporte na vida em geral.

No que tange a educação, esse marco conceitual utiliza essencialmente três conceitos, segundo a Pedagogia Freiriana Homem, Processo Educativo e Conteúdo.

Freire entendia o conceito: Homem como um ser inconcluso, consciente de sua inconclusão, e chamado a ser mais em permanente movimento de busca de ser mais, está sendo no presente, e tem esperança do futuro melhor, transformando-se diariamente (F reire, 1987).

Processo Educativo é o que se faz no contato do homem com o mundo vivido, não é estático, mas dinâmico, em contínua transformação e, portanto inacabado, em que os participantes percebem-se como escritores de suas próprias histórias (F reire, 1987).

Conteúdo de acordo com essa pedagogia é a dimensão discursiva, ideológica que busca dar ao real, a forma dos desejos e necessidades dos atores, através da formação da consciência, num esforço coletivo. Seu conteúdo supõe permanente construção de conhecimento de base científica para a produção de conhecimento viabilizador do próprio projeto político-pedagógico. Esse conteúdo é a relação da teoria com a prática e requer quatro elementos para a sistematização (S oethe, 1993): 1. tem como objeto a experiência e a prática concreta dos sujeitos; 2. pode constituir-se numa produção científica de conhecimentos, enquanto sustentada por uma base teórica epistemológica; 3 . pode causar rupturas com concepções e práticas anteriores, por imposição da novidade produzida; 4. enquanto processo coletivo de sistematização, supõe transformações coletivas e democráticas.

0 tema gerador pode surgir do grupo ou ser levado pelo animador. Nesse caso, tomei a decisão de levar o tema ajuda à família do cliente hospitalizado para, num processo de construção coletiva, aprender e trabalhar, buscando a transformação do mundo vivido, com a participação de todos como sujeitos.

\section{METODOLOGIA}

\section{CONSTRUINDO PASSO A PASSO O CAMINHO}

0 desenvolvimento desse trabalho se deu em cinco momentos distintos.

Guiada pela inter-relação dos conceitos do marco teórico o qual comporta minhas crenças e anseios de profissional, cidadã, que permeiam o meu fazer, venho procurando manter a proposta de desenvolver, já no acadêmico de Enfermagem, a visão da necessidade de se incluir o familiar no plano de cuidados do cliente, através de oficinas dentro de disciplinas curriculares. E mbora, não ofereça subsídios, de maneira estruturada à equipe de Enfermagem hospitalar, é uma maneira incipiente de socializar com elas, o ensino sobre 0 ajudar os familiares do cliente da Enfermagem.

\section{MONTAGEM DO PROJETO SOLICITADO}

Assim, o primeiro momento aconteceu quando uma Chefia de Enfermagem do H.U. solicitou que fizéssemos um projeto junto à sua equipe, com objetivo de construir num trabalho coletivo, referente a ajuda à família do doente, visando sua interação com as famílias dos clientes internados na UTI, para minimizar o estresse da equipe nesses enfrentamentos.

A oficina é uma prática de trabalho que, sob a coordenação de duas pessoas, permite que todos troquem experiências, vivências e lembranças; pois tem caráter reflexivo e é desenvolvida de maneira descontraída. Oficina é ainda, um jeito de reunir pessoas, de estimulá-las a fazer questionamentos e a compreender o sentido de grupo. Sendo a meta da oficina a aprendizagem, contudo, na sua participação não se aprende apenas com a cabeça, só com o intelecto, a aprendizagem se dá também com o coração e o corpo, integrando dessa forma o saber, o sentir e o fazer. 0 grupo era composto por uma pedagoga, duas psicólogas 
e uma enfermeira/docente, que trabalhou na montagem e realização das oficinas, a partir do sub tema solicitados pelos profissionais do hospital. Então, realizou-se duas oficinas de duas horas de duração cada, com membros da equipe de Enfermagem dos setores Unidade de Internação Ginecologia e UTI, pois foi aberta e divulgada a participação para os demais funcionários do hospital. Elas foram realizadas com uma média de 15 pessoas por encontro e constava das seguintes atividades: Técnicas lúdicas para aquecimento de ações coletivas para trabalhar o tema, fechamento e avaliação por parte do grupo em relação a oficina. As oficinas foram realizadas no ambiente hospitalar, em sala reservada, equipada com colchonetes, quadro negro e outras instalações adequadas para o trabalho de grupo.

\section{TRABALHANDO NA OFICINA}

No segundo momento, trabalhamos com o grupo em oficinas. Inicialmente uma das coordenadoras propunha as tarefas a serem realizadas e explicava aos participantes o que lhes cabia fazer. $\mathrm{Na}$ execução e apresentação dessas atividades, as coordenadoras participavam do debate em torno das questões levantadas pelo grupo, auxiliando na reflexão e também fazendo registros.

A primeira oficina começou com a atividade denominada "Teia de Aranha". Constitui em realizar uma técnica de apresentação, utilizada também para captar as expectativas dos participantes em relação ao trabalho. Seu desenvolvimento ocorreu da seguinte maneira: solicitou-se aos participantes que formassem um círculo e uma das coordenadoras, segurando um novelo de lã colorida, se apresentou jogando-o para alguém do grupo. Por sua vez, aquele deveria se apresentar, expor suas expectativas e jogar o novelo para outro participante, segurando também um ponto do fio de lã e, assim o jogo deveria prosseguir até que todos tivessem falado. Ao final, observou-se uma teia no centro do círculo, representando o sociograma do grupo. A partir desta representação, uma coordenadora comentou que a mesma mostrava as ligações solidárias existentes entre seus componentes, que poderiam ser acionadas, quando necessário.

Continuando, as coordenadoras distribuíram o material entre os quatro subgrupos formados. Todos receberam como tarefa representar através de cartazes e figuras, as dificuldades na interação com a família. Ao final, os cartazes construídos expressaram conteúdos ricos e surpreendentes. Em todos ficou evidente 0 sentimento da equipe em querer auxiliar a família, mas a mesma reconhece que foge do contato por se sentir despreparada, atarefada e sem autonomia frente a determinadas situações, como por exemplo a notificação da morte, diagnóstico, prognóstico, etc. Em alguns cartazes, os subgrupos destacaram o quadro que o paciente e a família vivem no hospital que é: falta de informações compreensíveis, a angústia pela incerteza do prosseguimento da vida, a sombra da morte representada pela UTI e a não familiaridade com o ambiente dessa unidade.

\section{APROFUNDANDO A COMPREENSÃO COM ENTREVISTAS}

Buscando compreender o contexto real das relações entre equipe e família, após a realização das oficinas e análise dos dados emergidos delas, surge o terceiro momento, pois sentiu-se a necessidade de conhecer mais detalhadamente o cotidiano das famílias no hos pital, as normas formais e informais da instituição e a realidade das relações estabelecidas entre as famílias e os profissionais do hospital. Para isso, decorrido um semestre, criou-se um roteiro de entrevista, o qual continha seis perguntas para a equipe de Enfermagem e outras seis para a família. As entrevistas foram realizadas pelas próprias coordenadoras das oficinas, a quatro profissionais que participaram das atividades, durante seu turno de trabalho. E três familiares também foram entrevistados, durante o período de visita.

\section{TROCA INFORMAL}

Já o quarto momento ocorre quando as pessoas, durante seu trabalho, ao me encontrar no hospital ou "campus" universitário, se mostram interessadas na proposta e tiram dúvidas, constituindo-se uma oportunidade para reflexões e descoberta de conteúdo a ser trabalhado ainda com a equipe, já que esta demonstra abertura e necessidade desse aprendizado. 


\section{REFLETINDO A CONTRIBUIÇÃO DA PROPOSTA}

Por sua vez, o quinto momento acontece quando já decorrido um ano da primeira oficina, eu retorno aos componentes da equipe de Enfermagem que participaram da proposta, para realizar uma entrevista com questões semi-estruturadas. 0 propósito desse contato era perscrutar se as oficinas ajudaram a interagir melhor com a família, se desejavam obter alguma informação ou instrumentação a mais, se a escola poderia fazer algo e finalmente o que facilitaria a implementação dessa proposta.

\section{RIGOR ÉTICO}

Desde 0 início dos trabalhos em grupo, as coordenadoras firmaram um acordo verbal com a Chefia e os participantes, garantindo a liberdade para optar na continuação ou não dos trabalhos, bem como 0 anonimato dos mesmos e da instituição. Posteriormente foi solicitado autorização para utilizar parte dos dados das oficinas. E também as demais coordenadoras foram contatadas e autorizaram o uso dos dados para o presente trabalho.

\section{REGISTROS}

0 registro de todas as atividades, foi realizado através das fichas de avaliação preenchida pelos participantes das oficinas, anotações feitas por uma das coordenadoras, durante as mesmas, cartazes produzidos pelo grupo, relatórios elaborados imediatamente ao término dos encontros, assim como as gravações das falas, nas entrevistas, autorizadas.

\section{ANÁLISE}

A análise desses dados foi do tipo qualitativa, à luz do referencial teórico, de outros autores da sustentação teórica, e também baseada na minha experiência profissional.

\section{RESULTADOS E DISCUSSÃO DOS ACHADOS}

Dos assuntos abordados, tanto nas oficinas, entrevistas como nos encontros casuais emergiram três categorias principais: A família como parceira da equipe de Enfermagem na ajuda/cuidado do cliente. Trabalhar o tema morte contribuiu para minimizar o estresse dos componentes da equipe de Enfermagem. Limites impostos pela instituição que impedem a interação entre a equipe de saúde e a família do cliente hospitalizado.

$\mathrm{Na}$ primeira categoria, os atores refletiram que é vantagem para todos verem a família como parceira e não como entrave, na hora de tomar decisões. Reconhecem a necessidade da equipe diluir, com o cliente e a família o poder, para permitir-lhes participar de momentos importantes no tratamento do cliente. Ao estabelecer uma comunicação horizontal com os familiares, a equipe relata que inclui nas suas atividades, a preparação da família para falar com o doente, pois as pessoas se chocam ao ver seu familiar num ambiente desconhecido, conectado a aparelhos estranhos e num estado de saúde delicado, por vezes com a fisionomia deformada. Nessa parceria, realizam ainda, ações que compreendem: dar informações quanto à utilidade dos aparelhos, procurando com isso incentivar o diálogo, mesmo que o cliente não tenha condições de responder; estimulam ações de ajuda/cuidado como toque, massagem suave, palavras de fé, carinho, alimentação e participação em alguns procedimentos simples e leves - dos procedimentos mais pesados a família é poupada.

Ações como: o permitir a entrada de familiares com mais freqüência, impedir a presença de uma visita que o cliente não deseja, intermediar reconciliações, ou ainda liberar a entrada de pertences tal como telefone, perfume ou algo que o personalize, identifique e traga lembranças do seu mundo familiar, no meu entender são pequenos porém constitui o que Travelbee chama de ajuda. A necessidade de compartilhar com a família é mais do que humanizar o serviço, é uma maneira terapêutica de compreender a própria família, e esta em contrapartida, compreender a situação através do profissional. 
Agindo dessa forma, a equipe está reconhecendo a família como um significativo contexto de ajuda/ cuidado para a saúde de seus membros, por admitir que há uma complexa relação de múltiplos fatores entre a família e seus membros (Gillis, 1989).

A discussão da categoria morte contribuiu para minimizar o estresse dos membros da equipe de Enfermagem e envolveu os seguintes aspectos: Como se lida com a questão do morrer; o que é morte para cada um e para a equipe no hospital; o que significa a morte para o profissional que luta pela vida?

Essa categoria evidencia o reconhecimento de que é requerido dos profissionais conhecimentos de si mesmos, humildade e coragem para identificar-se e enfrentar-se com motivações e sentimentos pessoais na situação interpessoal (Travelbee, 1979). Afirmam que, o ambiente e a forma da condução da discussão em si, levou-os a refletirem e a aceitarem a sua própria finitude para aceitarem também a do outro. Essa reflexão, de maneira semelhante, foi útil para mostrar as limitações do ser humano e se tranqüilizar ao se saber não responsável pelo mundo, já que não é onipotente mas, que deve fazer sua parte com competência, a despeito do final da história do cliente.

A categoria limites impostos pela instituição que impedem a interação entre a equipe de saúde e a família do cliente hospitalizado é traduzida nas constatações relatadas a seguir: o cotidiano institucional oferece barreiras à permanência do familiar na forma de estabelecimento de horários rígidos; pouco ou falta de espaço e disponibilidade para esclarecer as dúvidas; falta de compartilhamento de sentimentos a respeito da situação em que a família se encontra; a não mediação dos caminhos para o fortalecimento da família, e não satisfação das suas necessidades emergentes durante essa situação; conteúdo das informações serem em nível de difícil entendimento aos familiares.

Há porém alguns trabalhadores que, conhecendo as limitações das regras e rotinas, se sentem despreparados emocional, instrumentalmente e sem autonomia para lidar com o cliente e seu familiar. Esses têm uma atitude de evitamento de contatos. Em ambos os casos, o doente e a família ficam sem o atendimento de suas necessidades básicas de afeto, segurança, apoio familiar e a família é privada de informações adequadas, afastada ou ignorada frente a decisões vitais a respeito dos encaminhamentos terapêuticos.

Esses resultados vêm mostrar a necessidade e ao mesmo tempo a viabilidade da instauração de um processo educativo proposto pela Pedagogia Freiriana explicitados por Soethe (1993).

\section{AVALIAÇÃO DOS MEMBROS DA EQUIPE DE ENFERMAGEM EM RELAÇÃO À PROPOSTA}

Essa avaliação teve $o$ intento de medir a efetividade da proposta de trabalhar a interação entre equipe de Enfermagem e a família do cliente hospitalizado, a fim de perceber sinais favoráveis à sua continuidade ou redirecionamento. Sob a perspectiva metodológica os participantes do projeto avaliaram-na quanto aos aspectos:

Forma - eles declararam que a oficina proporcionou-Ihes refletir e dialogar sobre o seu cotidiano de trabalho, configurando-se uma rara oportunidade de "ouvirem" seus sentimentos e colocando-se no lugar dos clientes e familiares, tomando assim, consciência de suas ações, escolhas e responsabilidades. o clima de descontração, característico nessa prática de trabalho, motivou a participação de todos, resultando em entrosamento e possibilidade para a discussão das dificuldades que cada um enfrentava no seu dia-a-dia de trabalho.

Conteúdo - a experiência em grupo permitiu aos participantes despertarem sua atenção para a família e as necessidades que esta enfrenta, bem como, refletir sobre as formas de solucionar as dificuldades e melhorar a interação entre a equipe e família apontada nas frases seguinte: saberei lidar com as minhas dificuldades e das demais pessoas junto à família; acrescentou-me mais conhecimento; trouxe à tona questões de enfrentamento necessários na profissão e à vida; despertou mais ainda a consciência do papel da Enfermagem à família.

Facilidades - no que diz respeito a facilidades na participação do projeto de ajuda à família, alguns participantes mencionaram que já é de sua própria índole "olhar" os familiares como alguém que está passando por uma crise e que por isso necessitam de ajuda. Outros, só agora com o trabalho, passaram a perceber que a família tem necessidades. Por isso passaram a compreender que se demorar um pouco mais, além do tempo necessário à execução de procedimentos técnicos, para terminar de ouvir o que o cliente/familiar está falando, 
também é ajudá-los sem que precisem sentir-se culpados pela "perda" de tempo, despendido nessa ação, constituindo um alívio.

Salientaram ainda como agente facilitador, a postura da enfermeira que acolhe tal proposta, pois não só permite a atuação dos demais elementos da equipe de Enfermagem na ajuda à família, mas também a incentiva.

Dificuldades - os membros da equipe de Enfermagem apontam como uma dificuldade para a interação da mesma, a não adesão total dos colegas à proposta, uma vez que não é obrigatória a presença em atividades como essa.

Sugestões - os participantes sugerem a continuação do trabalho. E que seja expandida aos demais setores do hospital. Deve-se descobrir uma estratégia que leve todos os integrantes da equipe de saúde, e não somente a da Enfermagem, a participarem de alguma atividade que trabalhe as relações interpessoais, numa forma de rodízio, a fim de que todos tenham a oportunidade e o compromisso de participarem ao passarem por essa atualização, trabalhar em permanente parceria com docentes, para que a proposta seja retroalimentada e atenda a novas necessidades.

Trabalhar sob a forma de oficinas, com alguns integrantes da equipe de Enfermagem, foi vivenciar o inter-relacionamento dos conceitos do marco teórico, olhando o trabalhador de saúde como um ser humano inconcluso, mas sujeito de um processo educativo. Combinando esse processo educativo com a teoria das Relações Interpessoais de forma lúdica, considerando as peculiaridades de cada ser humano, exercitou-se articular o próprio conceito relacionamento interpessoal, com de 0 amor e com o de Enfermagem.

Pessoalmente foi gratificante laborar nessa proposta, por dados como quando os participantes relataram terem crescido ao serem sujeitos de um processo de produção de conhecimento científico, que viabilizou 0 projeto no seu mundo vivido e não criado um ambiente artificial. Todavia, sinto que se mostrou insuficiente no número de encontros e no alcance do público alvo.

Contribuição efetiva, sem dúvida foi o fato de ter despertado, em nível individual, a consciência dos participantes que a família do doente também tem necessidades. Razão pela qual, se faz necessário aprofundar as reflexões sobre seus sentimentos, atitudes, crenças e limites para um posicionamento ético pelo bem comum, disponibilidade para incluir o outro como parceiro no seu trabalho, e desenvolver habilidades de relacionamento humano.

Para isso, no nível profissional, também é preciso um constante aprofundamento de seus conhecimentos sobre família, a ampliação do modelo de sua prática que possa permitir a interação com outros saberes como o pensamento interdisciplinar, de forma a aumentar as possibilidades de instrumentação, necessária para 0 trabalho com famílias.

De igual maneira é importante o "desenvolvimento de projetos interdisciplinares de assistência e pesquisa à família, a participação dos enfermeiros nas instâncias em que são tomadas decisões sobre políticas e programas, envolvendo a família, implementação e avaliação de novas metodologias de cuidar da família, socializando seus resultados, a criação de programas de assistência à família nos serviços de saúde, como parte dos programas, oferecidos à população" (Elsen, 1998).

Uma última consideração que faço é sobre a necessidade básica de que o ser humano tem de ser tratado com amor. Independente que ambiente seja, é imperativo dar e receber amor, quer no seu contexto familiar, no de trabalho, no social ou nos es paços públicos como é um serviço de saúde - na clínica cirúrgica no papel de cliente/familiar ou de componente da equipe de Enfermagem. Esse compromisso social a ser constituído é uma responsabilidade de todos nós.

ABSTRACT: This is the report of a program developed along with the nursing team of a school hospital which aimed at raising the social commitment from the nursing team to the hospitalized customer's family and the growth and development of the agents potentialities. It was used concepts of the (Relações Interpessoais) theory and of the (Pedagogia Problematizadora) as its theoretical reference. Metodologically it was used some strategies such as workshops, interviews and informal chats. The ethical rigour was observed both in the contact with the people involved as well as in the dealing with the data. The analysis was enlightened by the theoretical reference and the author's professional experience. The results show that the team considers having the family as a partner as an advantage; the death theme led them to recognize their finitude; they admit that there are institutional barriers that prevent the contact between the family and the customer. They consider the proposal 
as an opportunity to understanding the role of nursing to the family, something that should have continuity and be expanded to all hospital sections.

KEY WORDS: Nursing team; Health family.

RESUMEN: Se trata del relato de un programa desarrollado por un equipo de Enfermería de un hospital escuela, buscando propiciar compromiso social de ésta para con la familia del cliente hospitalizado, crescimiento y desarrollo de las potencialidades de los actores. Tuvo como referencial teórico conceptos de la teoría de las Relaciones Interpersonales y de la P edagogía P roblematizadora. Metodológicamente utilizaron estrategias de trabajos grupales, entrevistas e intercambio informal. Para el contacto con las personas y el tratamiento de los datos se tomó en cuenta el rigor ético. El análisis fue iluminado por el referencial teórico y experiencia profesional da la autora. Los resultados muestran que, el equipo ve como ventaja tener a la familia compartiendo; trabajar el tema muerte los llevó a reconocer su finitud; admiten que hay barreras institucionales para el contacto entre la familia y el cliente. Esta propuesta es evaluada como oportunidad de concientización del papel de Enfermería con la familia que debe tener continuidad y ser expandida a todos los sectores del hospital.

PALABRAS CLAVE: E quipo de enfermería; Salud de la familia.

\section{REFERÊNCIAS}

1 BAPTISTA, C. L. B. M. Convivendo e compreendendo: assistência de enfermagem ao paciente e a família no serviço de emergência. Florianópolis, 1995. Dissertação (Mestrado em Enfermagem) - Programa de Pós-Graduação em Enfermagem, Universidade Federal de Santa Catarina.

2 DAL SASSO, G. T. M. A crise como uma oportunidade de crescimento para a família que enfrenta uma doença aguda - um desafio para a enfermagem. Florianópolis, 1994. Dissertação (Mestrado em Enfermagem) - Programa de Pós-Graduação em Enfermagem, Universidade Federal de Santa Catarina.

3 DOMINGUEZ, B. N. R. Programa da saúde da família: como fazer uma. Computação Gráfica e Editora. 1998.

4 ELSEN, I. et al. Marcos para a prática de enfermagem com famílias. Florianópolis: Ed. UFSC, 1994. 195p.

5 ELSEN, I. et al. A enfermagem e a família: bases para seu desenvolvimento. Florianópolis: Gapefam, 1998.

6 FRANCO, M. C. Situação do familiar que acompanha um paciente adulto internado em um hospital geral. Florianópolis, 1988. Dissertação (Mestrado em Enfermagem) - Programa de Pós-Graduação em Enfermagem, Universidade Federal de Santa Catarina.

7 FREIRE, P. Pedagogia do oprimido. 17.ed. São Paulo: Paz e Terra, 1987.

8 GILLISS, C. L. et al. Toward a science of family nursing. Califórnia: Addison-Wesley, 1989.

9 GRÜDTNER, D. I. A família na UTI. Rev. Centro Ci. Saúde, Florianópolis, v.8, n.1/2, p. 176-180, jan./jun. 1994.

10 GRÜDTNER, D. I. Processo educativo participativo com enfoque na ajuda à família: uma experiência na disciplina de enfermagem cirúrgica. Florianópolis: 1997. Dissertação (Mestrado em Enfermagem) - Universidade Federal de Santa Catarina.

11 NIETSCHE, E. A. As teorias de educação e o ensino da enfermagem no Brasil. In: SAUPE, R. (Org.). Educação em enfermagem. Florianópolis: Editora da UFSC, 1998. p.119-162.

12 ROSA, E.; ROSINI, I.; CANEVER, L. A. Necessidades humanas básicas dos familiares de pacientes internados na UTI. Florianópolis, 1996, Monografia (Especialização em Saúde Familiar) - Universidade Federal de Santa Catarina - GAPEFAM.

13 SANTOS, R. L. Educação, enfermagem e prática profissional com famílias: vivências de professores de um curso de graduação. Porto Alegre, 1996. Tese (Doutorado) - Faculdade de Educação da PUCRS, Pontifícia Universidade Católica do Rio Grande do Sul.

14 SOETHE, J. R. Educação popular: concepções históricas, construção de paradigmas e teoria-prática. Série Movimentos Sociais e Cultura, v.9, n.3, 1993.

15 TRAVELBEE, J. Intervencion en enfermeria psiquiátrica: el processo de la relacion de persona a persona. Cali: Carvajal. 